\title{
Green Approach to Develop Bee Pollen-Loaded Alginate Based Nanofibrous Mat
}

\author{
Ayben Pakolpakçı1 *(i) and Zbigniew Draczynski (D)
}

check for

updates

Citation: Pakolpakçıl, A.;

Draczynski, Z. Green Approach to

Develop Bee Pollen-Loaded Alginate

Based Nanofibrous Mat. Materials

2021, 14, 2775. https://doi.org/

$10.3390 / \mathrm{ma} 14112775$

Academic Editors: Andrei

V. Petukhov and Francisco

Javier Espinach Orús

Received: 3 April 2021

Accepted: 21 May 2021

Published: 24 May 2021

Publisher's Note: MDPI stays neutral with regard to jurisdictional claims in published maps and institutional affiliations.

Copyright: (C) 2021 by the authors. Licensee MDPI, Basel, Switzerland. This article is an open access article distributed under the terms and conditions of the Creative Commons Attribution (CC BY) license (https:// creativecommons.org/licenses/by/ $4.0 /)$.

\author{
Faculty of Material Technologies and Textile Design, Lodz University of Technology, 116 Żeromskiego Street, \\ 90-924 Lodz, Poland; zbigniew.draczynski@p.lodz.pl \\ * Correspondence: ayben_p@yahoo.com
}

\begin{abstract}
Green electrospun materials are gaining popularity in the quest for a more sustainable environment for human life. Bee pollen (BP) is a valuable apitherapeutic product and has many beneficial features such as antioxidant and antibacterial properties. Alginate is a natural and low-cost polymer. Both natural materials show good compatibility with human tissues for biomedical applications and have no toxic effect on the environment. In this study, bee pollen-loaded sodium alginate and polyvinyl alcohol (SA/PVA) nanofibrous mats were fabricated by the electrospinning technique. The green electrospun nanofibrous mats were analyzed by scanning electron microscopy (SEM), Fourier transforms infrared spectroscopy (FTIR), and differential scanning calorimeter (DSC). According to the findings of the study, the toxin-free electrospinning method is suitable for producing green nanomaterial. Because of the useful properties of the bee pollen and the favorable biocompatibility of the alginate fibers, the bee pollen-loaded SA/PVA electrospun mats have the potential for use in a variety of biomedical applications.
\end{abstract}

Keywords: bee pollen; nanofiber; biomaterial; green production; electrospinning

\section{Introduction}

In the past ten years, electrospinning has achieved great interest from the scientific community for its ability to create green micro and nanoscale polymeric fiber that is in high demand due to the use of cheap raw materials, non-toxic solvents, and the effectiveness of the fabrication technology for mass production of these products. According to the Grand View Research Inc. report, the global nanofibers market size was estimated at USD 477.7 million in 2016. Changes in customer and product trends drive the market. It is expected that the manufacture of a wide range of products from composite nanoscale fibers will drive industry innovation and thus increase its penetration in the medical, automotive, and textile markets [1].

Nanofiber structures have superior properties, such as high surface area and adjustable porosity. As a result, the use of these materials has been extensively researched in a variety of fields, including wound dressing, scaffolding, filtering, and packaging. Electrospinning is a simple, inexpensive, and green process capable of generating nanofibers. In the electrospinning process, the polymer solution is extruded by the electric field force from the capillary tube, and a Taylor cone can be formed at the end of the capillary. Positive charges accumulate on the surface of the Taylor cone as the electric field density increases, overcoming the surface tension and causing the spray of fluid. The solvent evaporates quickly, resulting in a continuous ultra-fine polymer fiber [2,3].

Since ancient times, bee products have been used in the medical field. In recent years, many researchers have become interested in developing bionanomaterials using bee products [4]. The use of bee products, such as honey [5-15] and propolis [16-25], for developing nanofibrous biomedical applications has been studied extensively. Bee pollen is another bee product that may well influence human health. It is used for the health benefits it brings due to its anti-carcinogenic, antioxidant, anti-inflammatory, antibacterial, 
and anti-allergic properties. Bee pollen is produced by the collection of floral pollen, from flowers and seedlings by stingless bees and honey bees, along with nectar or honey, bee secretions, wax, and enzymes. It consists of carbohydrates, proteins, amino acids, lipids, phenolic compounds, vitamins, and minerals [26-30].

Alginate is one of the most abundant natural polymers in the world. Sodium alginate (SA) is biodegradable, biocompatible and non-toxic, and is obtained from brown algae. Because of its structural similarities to the extracellular matrix, and its gelling properties under conditions compatible with biological activities, it is widely used in biomedical engineering applications, for example, drug delivery, in vitro cell culture, wound healing, and tissue engineering [31-33]. Electrospun alginate-based nanofibers have been developed for use in biomedical applications such as wound dressing [34-36], tissue engineering [37,38], and drug delivery systems $[39,40]$. The SA polymer in a water-based solution cannot be electrospun alone due to its inadequate chain entanglements. Polyvinyl alcohol (PVA) or polyethylene oxide (PEO) is usually used to accompany the electrospinning of sodium alginate. PVA is a hydrophilic linear polymer, and it has useful properties such as low toxicity, water-solubility, biocompatibility, and biodegradability [41].

It has been suggested that using a combination of bee pollen and alginate to develop green nanofibrous material could be an alternative method in bioengineering. As yet, there has been no study investigating the development of bee pollen-loaded polymeric nanofiber. In this study, bee pollen-loaded alginate-based nanofibrous mats were fabricated by electrospinning technique (Figure 1). The morphology, chemical composition, and thermal properties of the electrospun mats were investigated. The study results revealed that the bee pollen-loaded alginate-based nanofibrous materials are an environmentally sustainable material using the green electrospinning technique.

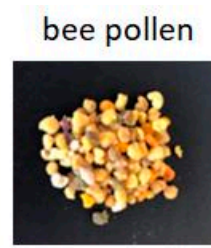

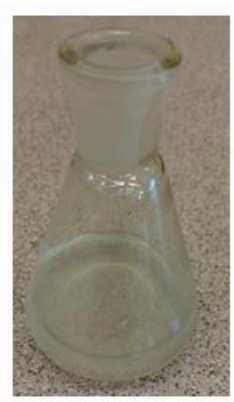

SA/PVA solution

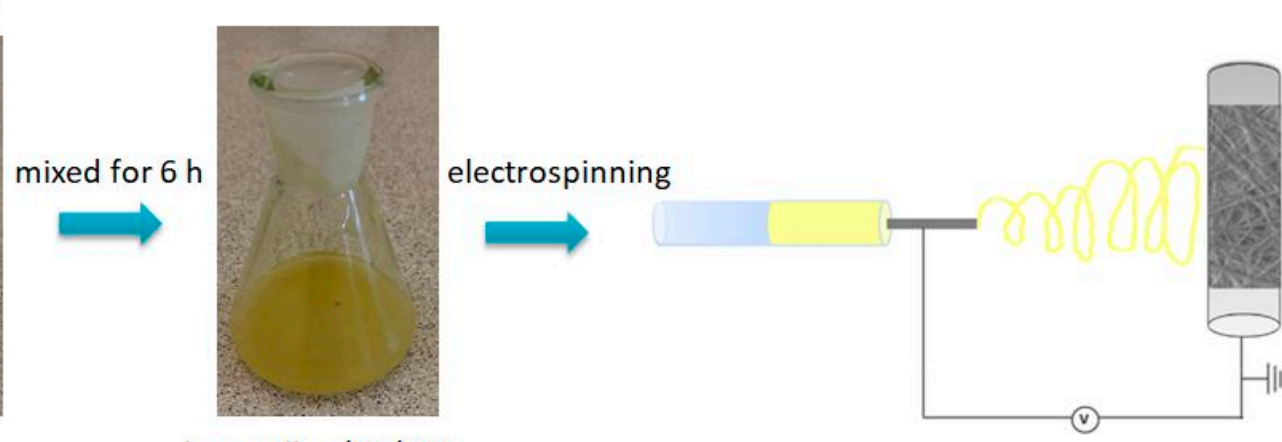

bee pollen/SA/PVA solution

Figure 1. Scheme of the bee pollen-loaded SA/PVA electrospun nanofibrous mats fabrication by electrospinning.

\section{Experimental}

\subsection{Materials}

Bee pollen was purchased from the local market (Apipol-Farma Sp. zo.o, Myslenice, Poland). SA polymer was obtained from Cargill Inc. (Minneapolis, MN, USA) and PVA $\left(\mathrm{M}_{\mathrm{W}} 85,000-124,000 \mathrm{~g} / \mathrm{mol}\right.$ with $87-89 \%$ hydrolysis) polymer was purchased from Sigma Aldrich (Sigma-Aldrich Sp. Zoo, Poznan, Poland). The deionized water (DE 20 Plus-Polna, Przemysl, Poland) was used throughout the experimental study. 


\subsection{Methods}

\subsubsection{Preparation of Solutions for Electrospinning}

Electrospinning polymer solutions were prepared by stirring $10 \mathrm{~g}$ PVA in deionized water $(100 \mathrm{~mL})$ for $6 \mathrm{~h}$ at $90^{\circ} \mathrm{C}$ temperature and $2 \mathrm{~g} \mathrm{SA}$ in deionized water $(100 \mathrm{~mL})$ for $4 \mathrm{~h}$ at $50^{\circ} \mathrm{C}$ temperature. Then, the two polymer solutions were mixed in a 4:1 (volume: volume) ratio. The various concentrations of bee pollen $(1,2$, and $3 \mathrm{~g}$ ) were added to the $\mathrm{SA} / \mathrm{PVA}(100 \mathrm{~mL})$ solutions and mixed for $6 \mathrm{~h}$ to get homogeneous solutions.

\subsubsection{Electrospinning Process}

The nanofibrous mats were produced in an electrospinning device (home-made design, Lodz University of Technology, Lodz, Poland) with the prepared solutions. The SA/PVA and the bee pollen-loaded SA/PVA electrospinning solutions were placed in a plastic syringe tube (ALMO-Erzeugnisse Erwin Burch GmbH, Bad Arolsen, Germany) fed through a metal nozzle of $0.6 \mathrm{~mm}$ inner diameter (KD-Fine, $\mathrm{KDM}^{\circledR} \mathrm{KD}$ Medical $\mathrm{GmbH}$, Berlin, Germany). The nanofibrous mats were attained at a flow rate of $0.8 \mathrm{~mL} / \mathrm{h}$ with an applied voltage of $25 \mathrm{kV}$. The nozzle-tip-to-collector distance was fixed at $15 \mathrm{~cm}$. A drum collector at $200 \mathrm{rpm}$ was covered with aluminum foil and samples were collected on it. All solution preparations and electrospinning processes were carried out at room conditions (temperature $=25 \pm 2{ }^{\circ} \mathrm{C}$; relative humidity $=50 \pm 5 \%$ ). The samples were named SA/PVA, 1BP-SA/PVA, 2BP-SA/PVA and, 3BP-SA/PVA, respectively.

\subsubsection{Measurements and Characterizations}

An apparent viscometer (Brookfield Viscometer RV-DV II, AMETEK Brookfield, Middleboro, USA) was used to measure the Brookfield viscosity of the electrospinning solutions at room temperature $\left(25 \pm 2{ }^{\circ} \mathrm{C}\right)$ using an SC4-27 spindle at a constant speed of $100 \mathrm{rpm}$. A conductivity meter (Bonajay Multifunction EC Meter, Bonajay Technology Co., Ltd., Shenzhen, China) was used to determine the conductivity of the electrospun solutions. Three measurements were performed. The mean and standard deviation values of the conductivity and apparent viscosity were calculated.

A scanning electron microscope (Nova ${ }^{\mathrm{TM}}$ NanoSEM 230, FEI Company, Hillsboro, OR, USA) was used for morphology observation of the SA/PVA and the bee pollenloaded SA/PVA nanofibrous mats. Image J software (National Institutes of Health and the Laboratory for Optical and Computational Instrumentation (LOC), Madison, WI, USA) was used to measure the diameter of the fiber. At least 100 measurements were taken from the SEM images of samples. The mean and standard deviation of the measurements were calculated.

The functional groups of the bee pollen and the SA/PVA, and the bee pollen-loaded SA/PVA nanofibrous mats) were analyzed by FTIR-ATR (Attenuated Total Reflectance) spectroscopy (Nicolet 6700, Thermo Electron Corp., Madison, WI, USA). The spectra were obtained by recording samples from a wavelength of $600-4000 \mathrm{~cm}^{-1}$. SpectraGryph software was used for investigation (Dr. Friedrich Menges, Oberstdorf, Germany).

Thermal behavior of the SA/PVA and the bee pollen-loaded SA/PVA nanofibrous mats were investigated using a differential scanning calorimeter (DSC Q2000, TA Instruments, New Castle, DE, USA). The electrospun samples were weighed and sealed in aluminum pans. Then, the temperature was elevated from room temperature to $220^{\circ} \mathrm{C}$ at a heating rate of $20^{\circ} \mathrm{C} / \mathrm{min}$ under a nitrogen atmosphere. TA Universal Analysis 2000 software was used for investigation (TA Instruments, New Castle, DE, USA).

\section{Results}

\subsection{Properties of Electrospinning Solutions}

The process of electrospinning and the morphology of the electrospun nanofibers are influenced by solution parameters. Viscosity and electric conductivity are key factors [2,3] Thus, before the electrospinning process, these parameters were determined. The electrical conductivity and apparent viscosity of the SA/PVA solution and SA/PVA solutions 
containing bee pollen are shown in Figure 2. The SA/PVA solution exhibited the lowest apparent viscosity of $801 \mathrm{cP}$. The addition of bee pollen to the SA/PVA solution increased the electrospinning solutions' apparent viscosity. The SA/PVA solution with 3 weight $\%$ bee pollen concentration exhibited the highest apparent viscosity of $860 \mathrm{cP}$. The SA/PVA solution had the lowest conductivity at $1828 \mu \mathrm{S} / \mathrm{cm}$, while the SA/PVA solution with 3 weight $\%$ bee pollen had the highest conductivity at $1998 \mu \mathrm{S} / \mathrm{cm}$.

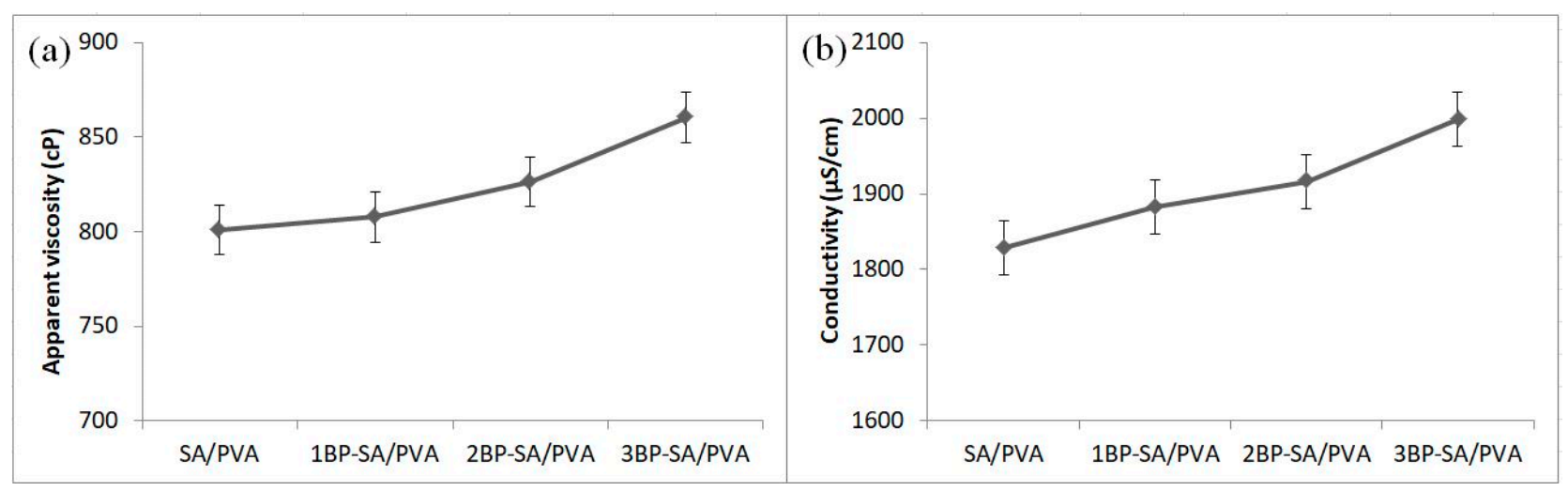

Figure 2. Apparent viscosity (a) and conductivity (b) of the electrospinning solutions with varying bee pollen content: 0,1 , 2 , and 3 weight $\%$.

\subsection{Morphology of the Nanofibrous Mats}

The morphological images and fiber diameter distributions of the electrospun SA/PVA and bee pollen-loaded SA/PVA nanofibrous mats are shown in Figure 3. SEM images demonstrated that the electrospun SA/PVA nanofibrous mat exhibited randomly oriented fibers with almost the same diameter along their lengths in the strip, and it lacked any beads (Figure 3a). It has been reported that the average fiber diameter of SA/PVA nanofibers is between 150 and $250 \mathrm{~nm}$ [42]. In this study, the average diameter of the electrospun SA/PVA nanofiber was $183 \mathrm{~nm}$. This result is similar to the literature. The morphology of the electrospun SA/PVA nanofibrous mats containing different quantities of bee pollen indicated that the randomly oriented fibers had similar diameters along their lengths in the strip, as well as a few beads (Figure 3b-d). The presence of bee pollen in the SA/PVA solution negatively affected the electrospinning process results when comparing sample SEM images (Figure 3b-d). With the presence of bee pollen in the SA/PVA solutions, the average diameter of the nanofibrous mats decreased. The average fiber diameter of the electrospun bee pollen-loaded SA/PVA nanofibrous mats was found to be in the range of 100-150 nm. This may result in increased conductivity of the electrospinning solutions, which causes the jet to stretch more [2,3], resulting in a thinner nanofiber diameter. The image (Figure 3) shows that SA/PVA nanofibrous mats had a smooth and uniform morphology, whereas bee pollen-loaded SA/PVA nanofibrous mats had a less uniform structure.

\subsection{FTIR Analysis}

The functional groups of bee pollen, SA/PVA, and bee pollen-loaded SA/PVA nanofibrous mats were determined by FTIR-ATR spectroscopy (Figure 4). The characteristic peaks of the bee pollen were observed at $3300 \mathrm{~cm}^{-1}, 2922 \mathrm{~cm}^{-1}, 1606 \mathrm{~cm}^{-1}, 1514 \mathrm{~cm}^{-1}$, and $1028 \mathrm{~cm}^{-1}$ were assigned to $\mathrm{OH}$ groups, $\mathrm{CH}$ stretching, CC stretching, and CO stretching, respectively. The outcome is consistent with the literature [43]. 

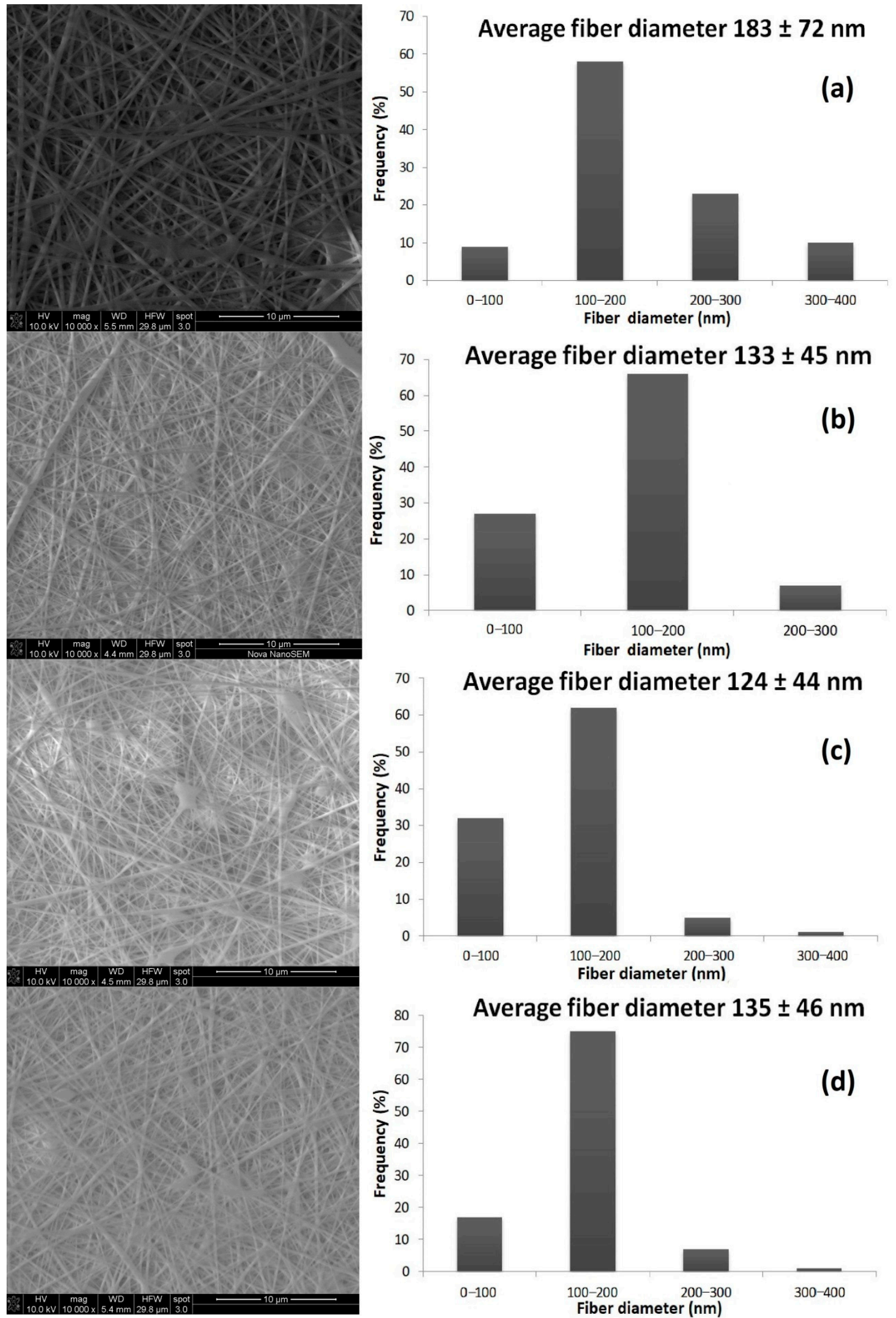

Figure 3. SEM images and fiber diameter distributions of the electrospun SA/PVA fibers obtained from (a) SA/PVA, (b) 1BP-SA/PVA, (c) 2BP-SA/PVA, and (d) 3BP-SA/PVA $(\times 10,000)$. 


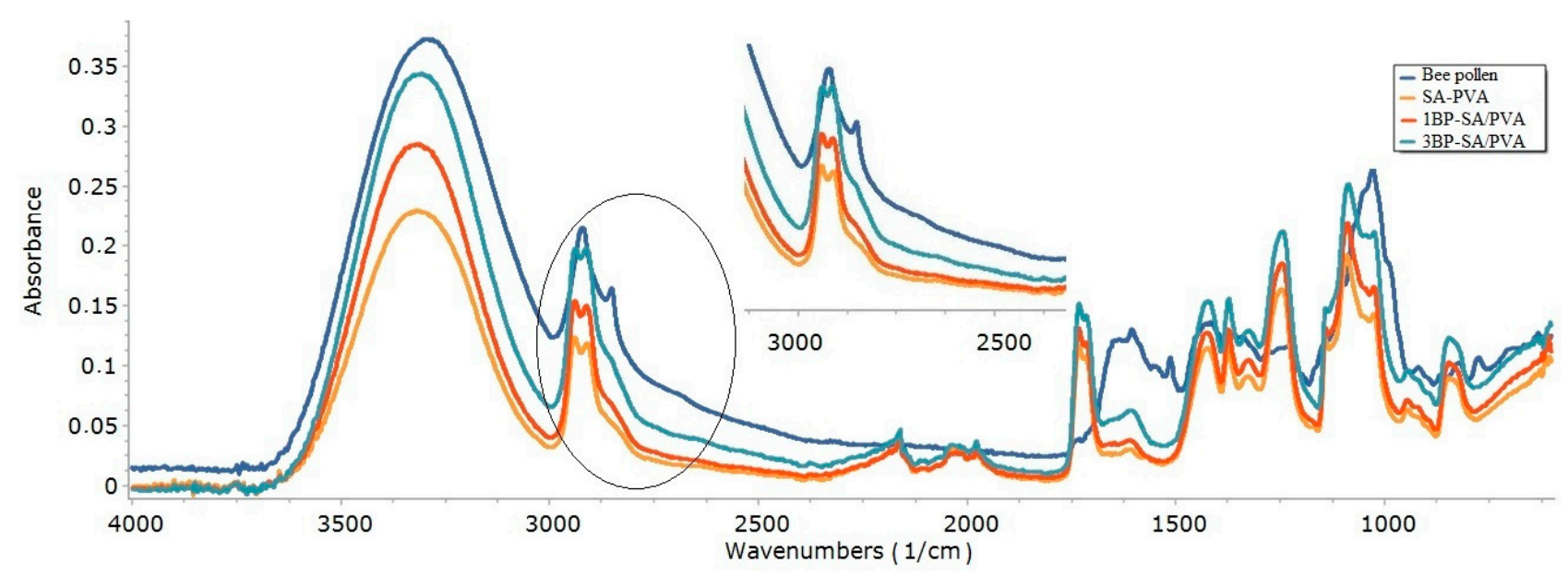

Figure 4. FTIR-ATR spectra of the bee pollen, the electrospun SA/PVA, and bee pollen-loaded SA/PVA nanofibers.

The characteristic peaks of the SA/PVA nanofiber were observed at $3310 \mathrm{~cm}^{-1}$, $2941 \mathrm{~cm}^{-1}, 1732 \mathrm{~cm}^{-1}$, and $1091 \mathrm{~cm}^{-1}$ were assigned to $\mathrm{OH}$ groups, $\mathrm{CH}$ stretching, and CO stretching, respectively $[36,41]$. The characteristic peaks of the electrospun bee pollenloaded SA/PVA nanofibers (1BP-SA/PVA and 3BP-SA/PVA) were observed at $3310 \mathrm{~cm}^{-1}$, $2939 \mathrm{~cm}^{-1}, 1732 \mathrm{~cm}^{-1}$, and $1088 \mathrm{~cm}^{-1}$ were assigned to $\mathrm{OH}$ groups, $\mathrm{CH}$ stretching and $\mathrm{CO}$ stretching, respectively. As a result of $\mathrm{CH}$ stretching vibrations of different groups in bee pollen, the adsorption bands in the frequency range of $2880-2860 \mathrm{~cm}^{-1}$ were broadened with the addition of bee pollen. Furthermore, the intensity of the absorption band resulting from the stretching of $-\mathrm{OH}$ groups increased, indicating that bee pollen hydroxyl groups were incorporated into the SA/PVA electrospun mat. While the maximum intensity of the hydroxyl of SA/PVA nanofiber was around 0.22 , the maximum intensity of hydroxyl increased from around 0.29 to 0.32 as the nanofibers bee pollen concentration increased from $1 \%$ to $3 \%$.

\subsection{DSC Analysis}

The thermal properties of the electrospun nanofibers were examined by differential scanning calorimeter. Glass transition and melting temperatures are two critical phenomena in polymers that are influenced by the materials' processing conditions and additives. DSC analysis provides important information about phase transitions within materials [44]. The DSC thermograms of the electrospun SA/PVA and bee pollen-loaded SA/PVA nanofibers are presented in Figure 5. Three endothermic peaks were observed on the DSC curve of the SA/PVA as well as bee pollen-laded SA/PVA. The first relaxation observed at 50-60 ${ }^{\circ} \mathrm{C}$, was due to relaxation in amorphous regions of PVA [44,45]. The second relaxation in the temperature range of $75-120^{\circ} \mathrm{C}$ was caused by the glass transition temperature of the water evaporation $[44,45]$ of PVA, and the third peak starting from $190^{\circ} \mathrm{C}$ was due to the melting temperature of the PVA. These results are consistent with the literature [44-46]. The glass transition temperature $\left(\mathrm{T}_{\mathrm{g}}\right)$ of the SA/PVA, 1BP-SA/PVA, 2BP-SA/PVA, and 3BP-SA/PVA nanofiber samples was determined to be around $76{ }^{\circ} \mathrm{C}, 95^{\circ} \mathrm{C}, 101^{\circ} \mathrm{C}$, and $105^{\circ} \mathrm{C}$, respectively. When bee pollen was incorporated into the SA/PVA nanofiber, there was no sharp peak in the melting temperature of the sample. The melting temperature $\left(\mathrm{T}_{\mathrm{m}}\right)$ of the SA/PVA, 1BP-SA/PVA, 2BP-SA/PVA, and 3BP-SA/PVA nanofiber samples was determined to be around $196^{\circ} \mathrm{C}, 192{ }^{\circ} \mathrm{C}, 190^{\circ} \mathrm{C}$, and $196{ }^{\circ} \mathrm{C}$, respectively. 


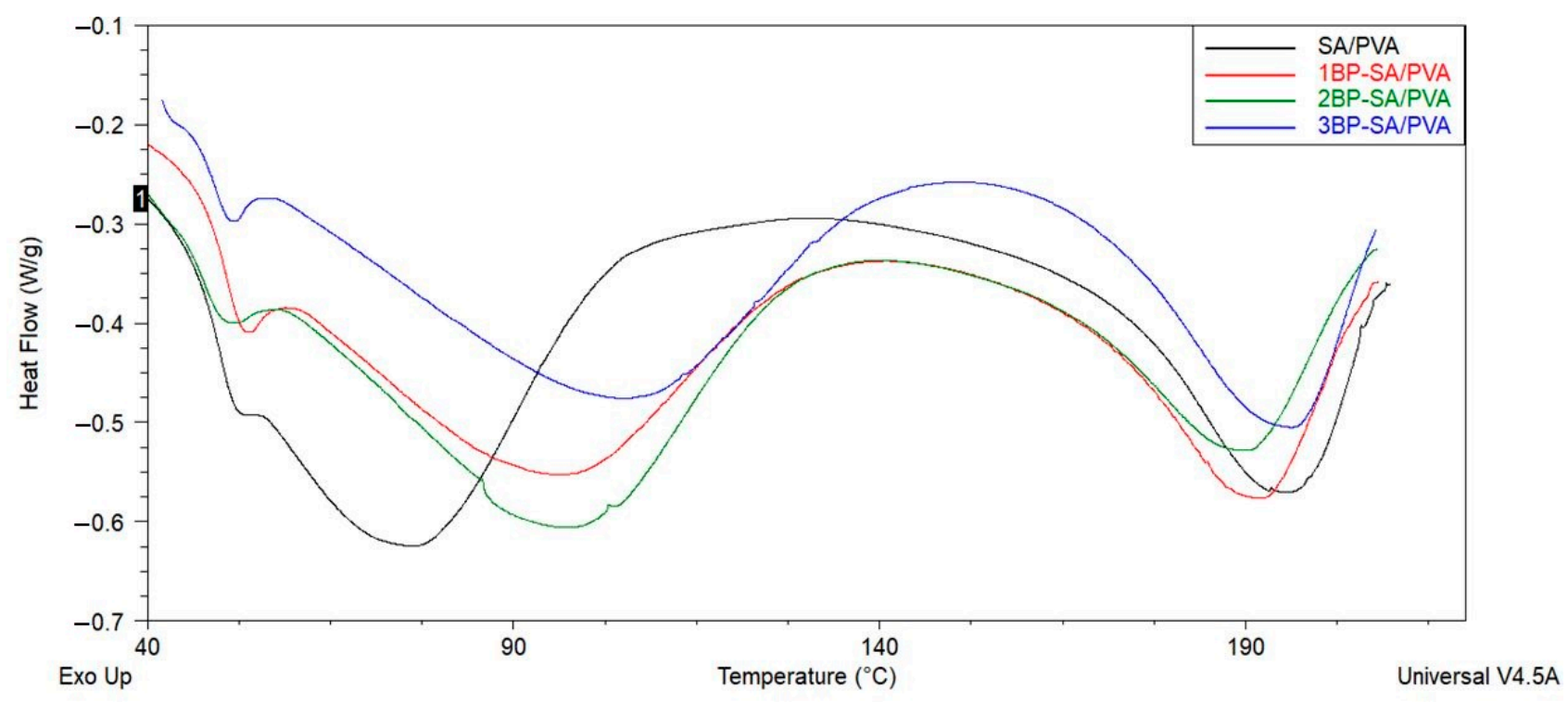

Figure 5. DSC thermograms of the electrospun SA/PVA and bee pollen-loaded SA/PVA nanofibers.

\section{Discussion}

Water was used as the solvent for the bee pollen, SA, and PVA polymers when preparing the electrospinning solutions. During the experiment, three different bee pollencontaining SA/PVA solutions were prepared. This demonstrated that bee pollen can be encapsulated into alginate-based nanofibers without the use of any harmful solvents. The approach has no negative consequences for human health and is also eco-friendly.

In general, the viscosity of the solution increased as the bee pollen concentrations increased. The increase in viscosity of the electrospinning solutions may be due to hydrogen bonding interactions between bee pollen and SA/PVA polymer mixtures. The presence of bee pollen in the SA/PVA solution increased the conductivity of the solution. Bee pollen contains micronutrients (iron, copper, zinc, manganese, silicon, and selenium) and macronutrients (calcium, phosphorus, magnesium, sodium, and potassium) [26,30]. Therefore this could also lead to an increase in the total quantity of ions in the solution.

To investigate the effect of the electrospinning solution composition on the structure of the nanofiber and electrospinning process, various solutions containing different amounts of bee pollen were prepared and used in the development of nanofiber. SEM images showed that the surface of the electrospun bee pollen-loaded SA/PVA nanofiber had a few defective structures. During the electrospinning process, it was observed although fairly smooth surfaces were produced at concentrations of 2 and 3 weight \% bee pollen, the obtained surfaces could not be properly stripped from the aluminum foil. This is thought to be due to the higher sugar content $[28,30]$ as the stickiness increased. Generally, the electrospun bee pollen-loaded SA/PVA nanofibers demonstrated a few imperfections with an average diameter of about $100 \mathrm{~nm}$. The tiny fiber and the highly porous structure of nanofiber is an advantage in biomedical applications, such as wound dressings and scaffolding. Because of these features, nanofibers can mimic the extracellular matrix (like collagen structure, scaffolds are composed of fibers with a diameter in the range of 50-500 nm) of normal skin or tissue and help promote cell growth and spread [31,32].

The FTIR-ATR spectra of the electrospun SA/PVA nanofibers changed after the addition of bee pollen, and the adsorption bands in the frequency range of $2880-2860 \mathrm{~cm}^{-1}$ were broadened due to $\mathrm{CH}$ stretching vibrations of different groups in bee pollen. The peak intensity of the stretching of -OH groups that occurs depending on the bee pollen concentration indicates the presence of bee pollen in the developed nanofibrous material.

An increase in the glass transition temperature $\left(\mathrm{T}_{\mathrm{g}}\right)$ and peak broadening indicated that the ordered association of the SA/PVA molecules was enhanced by the presence of 
bee pollen. Various factors can affect the glass transition temperature of the material, such as molecular structure and polar groups. It can be assumed that bee pollen decreased the segmental mobility of the polymer, thus inflexible groups increased $\mathrm{Tg}$ of nanofibrous material. Bee pollen molecules contain carboxyl groups $[47,48]$ and PVA molecules contain hydroxyl groups $[36,41]$. It is thought that hydrogen bonds are formed between these two groups. The formation of hydrogen bonds between bee pollen and SA/PVA causes improvement in the compactness and regularity of polymer chains. The thermal properties of the polymeric material depend on the mobility and compactness of the polymer chains and their crystalline structure in the material $[49,50]$. A minor change was observed in the melting temperature. This result showed that the presence of bee pollen in the SA/PVA nanofibrous mat did not significantly affect the melting temperature of samples.

Alginate has excellent biocompatibility, biodegradability, non-toxicity, gel-forming performance, and is easy to process [31,32]. Previous studies have indicated that bee pollen possesses antimicrobial, antifungal, antiviral, antioxidant, anti-inflammatory, immunostimulating, and local analgesic features [51,52]. Therefore, the bee pollen-loaded SA/PVA mats may have the potential to be used in several biomedical applications due to the beneficial properties of bee pollen and the desirable biocompatibility of SA and PVA polymers. The bee pollen-loaded SA/PVA electrospun mat is easy to fabricate and inexpensive, thanks to the use of an environmentally friendly nanotechnological production method. To the best of our knowledge, in our effort to develop a biomaterial using green electrospinning, we prepared a nanofibrous material based on SA/PVA loaded with bee pollen, which was produced for the first time. However, this study also showed that more research and work need to be done. This report is expected to play a leading role in future studies on this issue.

\section{Conclusions}

This work aimed to be the first approach to the use of bee pollen to obtain nanofibrous material by the electrospinning technique using a cheap, simple, and eco-friendly methodology. The study demonstrates the process and the characterization of the electrospun bee pollen-loaded alginate-based mat. The SEM images of the electrospun bee pollen-loaded alginate-based mats were mostly on a nanometer scale with the presence of a few defects. The incorporation of bee pollen into the SA/PVA electrospun mat was demonstrated by the FTIR spectrum. The DSC thermogram demonstrated that adding bee pollen into the SA/PVA polymer solution caused a remarkable change in the glass transition temperature but it had no significant effect on the melting temperature. The method for green electrospinning of water-based systems may be an alternative way to produce bee pollen-loaded alginate-based nanofibrous material. This study demonstrates how environmentally friendly nanofibrous materials can be designed for use in a wide range of fields, including biomedical applications such as, wound dressings and scaffoldings.

Author Contributions: Conceptualization, A.P.; methodology, A.P.; formal analysis, A.P.; investigation, A.P.; resources, Z.D.; writing—original draft preparation, A.P.; writing—review and editing, A.P. and Z.D.; visualization, A.P.; supervision, Z.D.; funding acquisition, Z.D. All authors have read and agreed to the published version of the manuscript.

Funding: This research received no external funding. The article processing charge (APC) was funded by Lodz University of Technology.

Institutional Review Board Statement: Not applicable.

Informed Consent Statement: Not applicable.

Data Availability Statement: Not applicable.

Acknowledgments: The authors extend their appreciation to the Faculty of Material Technologies and Textile Design at the Lodz University of Technology for supporting the work through the research.

Conflicts of Interest: The authors declare no conflict of interest. 


\section{References}

1. Grand View Research Inc. Nanofibers Market Size, Share \& Trends Analysis Report, 2017-2024. Available online: https: //www.grandviewresearch.com/industry-analysis/nanofibers-market (accessed on 1 March 2021).

2. Pillay, V.; Dott, C.; Choonara, Y.E.; Tyagi, C.; Tomar, L.; Kumar, P.; Toit, L.C.; Ndesendo, V.M.K. A review of the effect of processing variables on the fabrication of electrospun nanofibers for drug delivery applications. J. Nanomater. 2013, 2013, 789289. [CrossRef]

3. Haider, A.; Haider, S.; Kang, I.K. A comprehensive review summarizing the effect of electrospinning parameters and potential applications of nanofibers in biomedical and biotechnology. Arab. J. Chem. 2018, 11, 1165-1188. [CrossRef]

4. Kurek-Górecka, A.; Górecki, M.; Rzepecka-Stojko, A.; Balwierz, R.; Stojko, J. Bee Products in Dermatology and Skin Care. Molecules 2020, 25, 556. [CrossRef]

5. Arslan, A.; Şimşek, M.; Aldemir, S.D.; Kazaroğlu, N.M.; Gümüşderelioğlu, M. Honey-based PET or PET/chitosan fibrous wound dressings: Effect of honey on electrospinning process. J. Biomater. Sci. Polym. Ed. 2014, 25, 999-1012. [CrossRef]

6. Sarhan, W.A.; Azzazy, H.M.E.; El-Sherbiny, I.M. The effect of increasing honey concentration on the properties of the honey/polyvinyl alcohol/chitosan nanofibers. Mater. Sci. Eng. C 2016, 67, 276-284. [CrossRef] [PubMed]

7. Khan, M.Q.; Lee, H.; Khatri, Z.; Kharaghani, D.; Khatri, M.; Ishikawa, T.; Im, S.S.; Kim, I.S. Fabrication and characterization of nanofibers of honey/poly(1,4-cyclohexane dimethylene isosorbide trephthalate) by electrospinning. Mater. Sci. Eng. C 2017, 81, 247-251. [CrossRef]

8. Sarkar, R.; Ghosh, A.; Barui, A.; Datta, P. Repositing honey incorporated electrospun nanofiber membranes to provide anti-oxidant, anti-bacterial and anti-inflammatory microenvironment for wound regeneration. J. Mater. Sci. Mater Med. 2018, 29, 31. [CrossRef]

9. Tang, Y.; Xingzi, L.; Liang, C.; Zhong, Z.; Xie, R.; Zhou, Y.; Wang, W. Honey loaded alginate/PVA Nanofibrous membrane as potential bioactive wound dressing. Carbohydr. Polym. 2019, 219, 113-120. [CrossRef] [PubMed]

10. Al-Musawi, S.; Albukhaty, S.; Al-Karagoly, H.; Sulaiman, G.M.; Alwahibi, M.S.; Dewir, Y.H.; Soliman, D.A.; Rizwana, H. Antibacterial Activity of Honey/Chitosan Nanofibers Loaded with Capsaicin and Gold Nanoparticles for Wound Dressing. Molecules 2020, 25, 4770. [CrossRef]

11. Kanimozhi, S.; Kathiresan, G.; Kathalingam, A.; Kim, H.S.; Doss, M.N.R. Organic nanocomposite Band-Aid for chronic wound healing: A novel honey-based nanofibrous scaffold. Appl. Nanosci. 2020, 10, 1639-1652. [CrossRef]

12. Mrunalini, K.G.; Kanuganti, J.S.; Sharma, C.S. Honey and curcumin loaded multilayered polyvinylalcohol/cellulose acetate electrospun nanofibrous mat for wound healing. J. Mater. Res. 2020, 35, 600-609.

13. Shahid, M.A.; Ali, A.; Uddin, M.N.; Miah, S.; Islam, S.M.; Mohebbullah, M.; Jamal, M.S.I. Antibacterial wound dressing electrospun nanofibrous material from polyvinyl alcohol, honey and Curcumin longa extract. J. Ind. Text. 2020. [CrossRef]

14. Ullah, A.; Ullah, S.; Khan, M.Q.; Hashmi, M.; Nam, P.D.; Kato, Y.; Tamada, Y.; Kim, I.S. Manuka honey incorporated cellulose acetate nanofibrous mats: Fabrication and in vitro evaluation as a potential wound dressing. Int. J. Biol. Macromol. 2020, 155, 479-489. [CrossRef] [PubMed]

15. Zekry, S.S.A.; Abdellatif, A.; Azzazy, H.M.E. Fabrication of pomegranate/honey nanofibers for use as antibacterial wound dressings. Wound Med. 2020, 28, 100181. [CrossRef]

16. Sutjarittangtham, K.; Sanpa, S.; Tunkasiri, T.; Chantawannakul, P.; Intatha, U.; Eitssayeam, S. Bactericidial effects of propolis/PLA nanofibres obtained via electrospinning. J. Apic. Res. 2014, 53, 109-115. [CrossRef]

17. Arıan, H.K.; Solak, H.H. Propolis extract-PVA nanocomposites of textile design: Antimicrobial effect on gram positive and negative bacterias. Int. J. Second. 2017, 4, 218-224. [CrossRef]

18. Moghaddam, A.B.; Shirvani, B.; Aroon, M.A.; Nazari, T. Physico-chemical properties of hybrid electrospun nanofibers containing polyvinylpyrrolidone (PVP), propolis and aloe vera. Mater. Res. Express 2018, 5, 125404. [CrossRef]

19. Yan, T.; Yan, T.; Zhang, M.; Shi, Y.; Li, Y. Dichloromethane-extract of propolis (DEP) and DEP/PLA electrospun fiber membranes. Fibres Text. East. Eur. 2018, 26, 57-62. [CrossRef]

20. Jaganathan, S.K.; Mani, M.P.; Prabhakaran, P.; Supriyanto, E.; Ismail, A.F. Production, blood compatibility and cytotoxicity evaluation of a single stage non-woven multicomponent electrospun scaffold mixed with sesame oil, honey and propolis for skin tissue engineering. Int. J. Polym. Anal. 2019, 24, 457-474. [CrossRef]

21. Khoshnevisan, K.; Maleki, H.; Samadian, H.; Doostan, M.; Khorramizadeh, M.R. Antibacterial and antioxidant assessment of cellulose acetate/polycaprolactone nanofibrous mats impregnated with propolis. Int. J. Biol. Macromol. 2019, 140, 1260-1268. [CrossRef]

22. Alberti, T.B.; Coelho, D.S.; de Prá, M.; Maraschin, M.; Veleirinho, B. Electrospun PVA nanoscaffolds associated with propolis nanoparticles with wound healing activity. J. Mater. Sci. 2020, 55, 9712-9727. [CrossRef]

23. Eskandarinia, A.; Kefayat, A.; Gharakhloo, M.; Agheb, M.; Khodabakhshi, D.; Khorshidi, M.; Sheikhmoradi, V.; Rafienia, M.; Salehi, H. A propolis enriched polyurethane-hyaluronic acid nanofibrous wound dressing with remarkable antibacterial and wound healing activities. Int. J. Biol. Macromol. 2020, 149, 467-476. [CrossRef]

24. Hajinezhad, S.; Razavizadeh, B.M.; Niazmand, R.; Ismael, G. Antimicrobial, mechanical, and physicochemical properties of ethylene vinyl alcohol (EVOH) extruded films blended with propolis. Int. J. Food Prop. 2020, 23, 2020-2032. [CrossRef]

25. Stojko, M.; Włodarczyk, J.; Sobota, M.; Karpeta-Jarząbek, P.; Pastusiak, M.; Janeczek, H.; Dobrzyński, P.; Starczynowska, G.; Orchel, A.; Stojko, J.; et al. Biodegradable Electrospun Nonwovens Releasing Propolis as a Promising Dressing Material for Burn Wound Treatment. Pharmaceutics 2020, 12, 883. [CrossRef] [PubMed] 
26. Campos, M.G.R.; Frigerio, C.; Lopes, J.; Bogdanov, S. What is the future of Bee-Pollen? J. ApiProd. ApiMed. Sci. 2010, 2, 131-144. [CrossRef]

27. Khider, M.; Elbanna, K.; Mahmoud, A.; Owayss, A.A. Egyptian honeybee pollen as antimicrobial, antioxidant agents, and dietary food supplements. Food Sci. Biotechnol. 2013, 22, 1-9. [CrossRef]

28. Pascoal, A.; Rodrigues, S.; Teixeira, A.; Feás, X.; Estevinho, L.M. Biological activities of commercial bee pollens: Antimicrobial, antimutagenic, antioxidant and anti-inflammatory. Food Chem. Toxicol. 2014, 63, 233-239. [CrossRef]

29. Olczyk, P.; Komosinska-Vassev, K.; Wisowski, G.; Mencner, L.; Stojko, J.; Kozma, E.M. Propolis modulates fibronectin expression in the matrix of thermal injury. Biomed. Res. Int. 2014, 748101. [CrossRef]

30. Arruda, V.A.S.; Santos, A.V.; Sampaio, D.F.; Araújo, E.S.; Peixoto, A.L.C.; Estevinho, L.M.; Almeida-Muradian, L.B. Brazilian bee pollen: Phenoliccontent, antioxidant properties and antimicrobial activity. J. Apic. Res. 2020, 1-10. [CrossRef]

31. Mokhena, T.C.; Mochane, M.J.; Mtibe, A.; John, M.J.; Sadiku, E.R.; Sefadi, J.S. Electrospun Alginate Nanofibers Toward Various Applications: A Review. Materials 2020, 13, 934. [CrossRef]

32. Varaprasad, K.; Jayaramudu, T.; Kanikireddy, V.; Toro, C.; Sadiku, E.R. Alginate-based composite materials for wound dressing application: A mini review. Carbohydr. Polym. 2020, 236, 116025. [CrossRef] [PubMed]

33. Pacheco, D.P.; Butnarasu, C.S.; Vangosa, B.F.; Pastorino, L.; Visai, L.; Visentin, S.; Petrini, P. Disassembling the complexity of mucus barriers to develop a fast screening tool for early drug discovery. J. Mater. Chem. B 2019, 7, 4940-4952. [CrossRef]

34. Pakolpakçll, A.; Karaca, E.; Becerir, B. Investigation of a natural $\mathrm{pH}$-indicator dye for nanofibrous wound dressings. IOP Conf. Ser. Mater. Sci. Eng. 2018, 460, 012020. [CrossRef]

35. Pakolpakçıl, A.; Osman, B.; Özer, E.T.; Şahan, Y.; Becerir, B.; Göktalay, G.; Karaca, E. Halochromic composite nanofibrous mat for wound healing monitoring. Mater. Res. Express 2019, 6, 1250c3. [CrossRef]

36. Pakolpakçıl, A.; Osman, B.; Göktalay, G.; Özer, E.T.; Şahan, Y.; Becerir, B.; Karaca, E. Design and in vivo evaluation of alginatebased $\mathrm{pH}$-sensing electrospun wound dressing containing anthocyanins. J. Polym. Res. 2021, 28, 50. [CrossRef]

37. De Silva, R.T.; Mantilaka, M.M.M.G.P.G.; Goh, K.L.; Ratnayake, S.P.; Amaratunga, G.A.J.; de Silva, K.M.N. Magnesium oxide nanoparticles reinforced electrospun alginate-based nanofibrous scaffolds with improved physical properties. Int. J. Biomater. 2017, 2017, 1391298. [CrossRef] [PubMed]

38. Xu, W.; Shen, R.; Yan, Y.; Gao, J. Preparation and characterization of electrospun alginate/PLA nanofibers as tissue engineering material by emulsion eletrospinning. J. Mech. Behav. Biomed. Mater. 2017, 65, 428-438. [CrossRef]

39. Pegg, C.E.; Jones, G.H.; Athauda, T.J.; Ozer, R.R.; Chalker, J.M. Facile preparation of ammonium alginate-derived nanofibers carrying diverse therapeutic cargo. Chem. Commun. 2014, 50, 156-158. [CrossRef]

40. Kyziol, A.; Michna, J.; Moreno, I.; Gamez, E.; Irusta, S. Preparation and characterization of electrospun alginate nanofibers loaded with ciprofloxacin hydrochloride. Eur. Polym. J. 2017, 96, 350-360. [CrossRef]

41. Aadil, K.R.; Nathani, A.; Sharma, C.S.; Lenka, N.; Gupta, P. Fabrication of biocompatible alginate-poly(vinyl alcohol) nanofibers scaffolds for tissue engineering applications. Mater. Technol. 2018, 33, 507-512. [CrossRef]

42. Najafi, S.; Gholipour-Kanani, A.; Eslahi, N.; Bahrami, S.H. Study on release of cardamom extract as an antibacterial agent from electrospun scaffold based on sodium alginate. J. Text. Inst. 2020, 1-9. [CrossRef]

43. Anjos, O.; Santos, A.J.A.; Dias, T.; Estevinho, L.M. Application of FTIR-ATR spectroscopy on the bee pollen characterization. J. Apic. Res. 2017, 56, 210-218. [CrossRef]

44. Koosha, M.; Hamid, M.; Shokrgozar, M.A.; Farokhib, M. Nanoclay-reinforced electrospun chitosan/PVA nanocomposite nanofibers for biomedical applications. RSC Adv. 2015, 5, 10479-10487. [CrossRef]

45. Krishnan, K.; Aonoa, M.; Tsuruoka, T. Thermally stable resistive switching of a polyvinyl alcohol-based atomic switch. J. Mater. Chem. C. 2018, 6, 6460. [CrossRef]

46. Thangavel, K.; Balamurugan, A.; Venkatachalam, T.; Ranjith, E.K. Structural, morphological and optical properties of ZnO nano-fibers. Superlattice Microst. 2016, 90, 45-52. [CrossRef]

47. Rzepecka-Stojko, A.; Stojko, J.; Kurek-Górecka, A.; Górecki, M.; Kabała-Dzik, A.; Kubina, R.; Moździerz, A.; Buszman, E. Polyphenols from Bee Pollen: Structure, Absorption, Metabolism and Biological Activity. Molecules 2015, 20, 21732-21749. [CrossRef] [PubMed]

48. Komosinska-Vassev, K.; Olczyk, P.; Kaźmierczak, J.; Mencner, L.; Olczyk, K. Bee pollen: Chemical composition and therapeutic application. Evid. Based Complement Alternat. Med. 2015, 297425. [CrossRef]

49. Deng, L.; Li, Y.; Feng, F.; Wu, D.; Zhang, H. Encapsulation of allopurinol by glucose cross-linked gelatin/zein nanofibers: Characterization and release behavior. Food Hydrocoll. 2019, 94, 574-584. [CrossRef]

50. Kamaci, D.U.; Peksel, A. Enhanced catalytic activity of 1 mmobilized phytase into polyvinyl alcohol-sodium alginate based electrospun nanofibers. Catal Lett. 2021, 151, 821-831. [CrossRef]

51. Abouda, Z.; Zerdani, I.; Kalalou, I.; Faid, M.; Ahami, M.T. The antibacterial activity of moroccan bee bread and bee-pollen (fresh and dried) against pathogenic bacteria. Res. J. Microbiol. 2011, 6, 376-384.

52. Graikou, K.; Kapeta, S.; Aligiannis, N.; Sotiroudis, G.; Chondrogianni, N.; Gonos, E.; Chinou, I. Chemical analysis of Greek pollen-antioxidant, antimicrobial and proteasome activation. Chem. Cent. J. 2011, 5, 33. [CrossRef] [PubMed] 